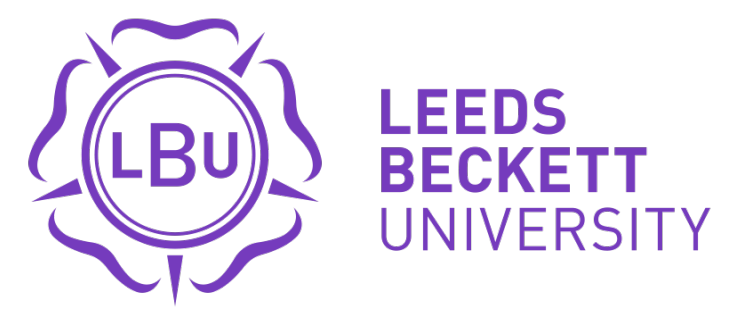

Citation:

Beech, $\mathrm{N}$ and Gold, $\mathrm{J}$ and Kershaw-Solomon, $\mathrm{H}$ and Auty, $\mathrm{T}$ and Down, $\mathrm{B}$ and Goodchild, J and Beech, S and Nisa, S (2020) Foresight and action learning supporting transition: An account of practice. Industry and Higher Education. ISSN 0950-4222 DOI: https://doi.org/10.1177/0950422220935379

Link to Leeds Beckett Repository record:

https://eprints.leedsbeckett.ac.uk/id/eprint/6947/

Document Version:

Article (Accepted Version)

The aim of the Leeds Beckett Repository is to provide open access to our research, as required by funder policies and permitted by publishers and copyright law.

The Leeds Beckett repository holds a wide range of publications, each of which has been checked for copyright and the relevant embargo period has been applied by the Research Services team.

We operate on a standard take-down policy. If you are the author or publisher of an output and you would like it removed from the repository, please contact us and we will investigate on a case-by-case basis.

Each thesis in the repository has been cleared where necessary by the author for third party copyright. If you would like a thesis to be removed from the repository or believe there is an issue with copyright, please contact us on openaccess@leedsbeckett.ac.uk and we will investigate on a case-by-case basis. 


\title{
Foresight and action learning supporting transition: an account of practice
}

\section{Authors:}

Nick Beech

Leeds Beckett University, UK

\section{Jeff Gold}

York Saint John University, UK

\section{Hazel Kershaw-Solomon, Tricia Auty, Bruce Down, Joanne Goodchild, Susan Beech and Shakiya Nisa}

Leeds Beckett University, UK

\section{Corresponding author:}

Nick Beech, Leeds Business School, Leeds Beckett University, Rose Bowl 404, City Campus, Leeds LS1 3HE, UK. Email: n.beech@leedsbeckett.ac.uk

\begin{abstract}
:
Integrating foresight into corporations has proved to be challenging. This account of practice reports on the introduction of futures and foresight (FF) teaching content into an executive Masters programme. The FF content was further linked to and provided a background for action learning sets. The purpose was to identify how introducing distant time horizons would help participants to adapt and change their perspectives in problem solving and professional development. The report describes how FF was incorporated across the programme and used to develop insightful conversations in the action learning sets. Citing two case examples, the authors reflect on how participants responded to these new elements and offer insights into the value of introducing FF as an interdisciplinary element in a programme.
\end{abstract}




\section{Keywords:}

Foresight, action learning, transition, practice, reflection

\section{Context}

The Leadership, Governance and People Management Subject Group at Leeds Business School has been delivering Masters management programmes customised for the military for over eight years. We provide recognition of prior learning (RPL), allowing experienced military leaders to enter the programme with advanced standing: this exempts them from three modules and shortens the duration of the course from 2 years to 18 months.

Each programme recruits up to 20 students and is made up of 4 modules delivered as 3-4 day learning blocks in the form of informal workshops. Assessment across the modules is via applied workbased assignments which include reflective elements. Whilst the programme is currently for a military cohort, its work-based focus makes it highly relevant to civilian managers as the applied nature of the assessments enables students to use their learning directly to improve professional practice and enhance their organisation's performance (Brennan et al., 2006).

In addition to providing conventional academic business and management content, the programme incorporates a range of multidisciplinary management tools to support the development of high-context skills, including coaching skills, foresight, action learning (AL) and reflective practice.

This report summarises experiences of the programme to date, highlights two specific instances of practice within it (Futures and Foresight and AL) and presents our key observations.

\section{Programme Purpose}

The teaching team in the period under consideration comprised 8 tutors, 4 of whom had military experience. The design of the programme is informed by Korthagen's (2004) 'Onion Model', which depicts learning as a multi-layered process. The Onion Model (Figure 1) surfaces the nature of an individual's external environment, the behavioural actions they take, and the competencies displayed and acquired, but it also delves deeper in an attempt to identify the self-beliefs and assumptions that may well inhibit growth. For example, with reagard to our present context, a substantial minority of military veterans experience difficulties with the transition into civilian life, a transition that may be hindered by a personal identity that is strongly linked to military masculinity (Higate, 2003).

Insert Figure 1 about here 
The final layer of the onion, mission, can be seen as a transpersonal layer which relates to a personal sense of meaning in our own existence and how we see ourselves in relation to the world. This deep inner layer shapes our purpose and how we think about ourselves, and inspires us to do what we do with our lives.

The purpose of the course was to help practitioners expand and apply theoretical knowledge to their working practice and to develop the key skills and behaviours they needed as professional managers. The aim of the practice-led curriculum was to develop an advanced knowledge of effective management so that the participants would be able to apply that knowledge to dynamic and complex issues, both systematically and creatively.

Through enabling them to reflect on their experiences, we attempted to raise their awareness of their inner needs and 'wittiness thinking' (Shotter, 2006), so helping them to build their cognitive comprehension by structuring and restructuring their understanding of their actions and the nature of their personal and professional selves. We also helped the participants to appreciate the multi-layered nature of learning and the need for conscious alignment in shaping one's individual disposition and actions which can be used to support personal transition in the process of change.

\section{Transition}

It was noted, during the designing of the course, that personal transition had significance for both military and civilian leaders. Transition can be broadly defined as 'any event or non-event [something not happening] that results in changed relationships, routines, assumptions, and roles' (Goodman, et al., 2006, p. 33). Transition is a personal and inner experience, as opposed to change which is an external event. It represents a shift of identity or agency through the influence of social norms and values, particularly from institutions, culture and life histories (Ecclestone et al. 2010). A transition may take years to come to terms with, and in some cases can be accommodated but never fully resolved. Transition is continuous and dynamic process, a lived experience (Anderson, 2012, p. 59) as people come to terms with their external world. The process can thus be seen in terms of Korthagen's (2004) onion layers of mission, identify and belief and, in turn, competencies and behaviours.

\section{Course Themes}

Three multidisciplinary recursive themes - reflection, action learning and future focus - ran through the modules. The aim was to enact a 'spiral curriculum' (Bruner 1960) by providing a scaffolding that would enable participants to explore their learning progressively. Participants were encouraged to apply their learning to practice, but also to reflect on and revisit their learning throughout the programme. The object was to provide the opportunity to look more deeply into what and how students learned; to explore experience, interconnectedness and multi-layered learning. We found action learning sets (ALS) to be particularly effective in facilitating this process as the participants moved through the programme. 


\section{Futures \& Foresight}

A newly introduced interdisciplinary element of the programme was Futures \& Foresight (FF), which consisted of one 1.5 hour session in each of the four modules. It involved systematically attempting to acquire informed insights into longer-term possible futures (Armstrong, 1985; Cuhls, 2003). Participants were asked to think about different futures, to anticipate change and to imagine future scenarios. They were then asked, in light of this thinking, to consider what strategic challenges and choices they might face in the long term. The aim was to encourage the development of future-focused mindsets (Hines and Gold, 2014), so that they could more effectively and proactively navigate an uncertain and unpredictable future. The point was not so much to predict what would happen but to see things in new ways (Meyer and Land, 2003), to perceive new horizons and to be ready to adapt and take action in a variety of circumstances.

Working as an AL group, participants were asked to select a core topic and pose questions that had unpredictable answers, horizon-scan for patterns and trends relating to the questions, project possible answers and identify 4-6 plausible future scenarios 10 years ahead. They were then tasked to reverse-extrapolate by working backwards, in 5-year time slots, using scenarios for 2029 to identify likely antecedents in 2024, then using the assumptions for 2024 to identify likely antecedents from 2019.

Whilst FF is focused on external events, it raises questions for students about personal development and alignment with their world to inform their decision making (Miles, and Keenan, 2003) and help them to become more future-ready. We encouraged participants to visualise and discuss with their peers the different options the future might hold, from which they could then evaluate the paths (with benefits and drawbacks) that could be taken (Hines and Gold, 2014). An example of a participant's submission is presented in Table 1 - this submission provided an influential backdrop and stimulus for deep conversations both in the FF class and in the ALS.

Insert Table 1 about here

\section{Programme Structure - Modules}

Leadership, Self and Creating the Future. This module provided the space for students to explore leadership, personal development and future focus. It also involved them in a critical review of their leadership competencies and capabilities in the context of their current and future professional aspirations, and to develop a more critical understanding of the nature of their own leadership so that they could consider how they wanted to develop.

The module introduced reflective practice, AL and ALS and the threshold concept (Meyer and Land, 2003) the latter employed to explore the nature of learning in that it can be transformative, 
irreversible, integrative, bounded, sometimes troublesome and that it can oscillate between old and emergent understandings (Cousin, 2006) but in so doing it can help us to see the world in new ways. The module further introduced the use of rich pictures (Checkland and Scholes, 1990) as tools to help participants review, visualise, evoke insights and discuss their experiences and understanding, themes that were echoed throughout the programme.

The Board, the Executive and Good Governance. In this module participants explored the world of corporate governance and reflected on the role of the board and directors. They looked at the role of strategic leadership through alternative prisms, including the critique of core governance theory, such as agency (Berle \& Means, 1932; Jensen \& Meckling, 1976), stakeholders (Freeman, 1984; Freeman, $\&$ McVea, 2001) and stewardship (Donaldson, 1990), and how they influence practice.

Work-Based Learning Exploration. This module provided an applied learning route, enabling participants to design their own work-based learning experiences. Discrete elements considered 'strategy as practice' (Mintzberg, 1973, Whittington, 1996; Jarzabkowski, 2005), exploring how strategies unfold over time. This included exploring concepts such as dynamic capabilities (Teece, 2007) where organisations learn to adapt by developing the analytical systems to collectively sense and seize opportunities by reconfiguring their competences to build new capabilities to meet the challenges of their environment. The module explored strategy as an evolving process, shaping patterns of action, highlighting how practitioners and their interactions influence the crafting of strategy (Vaara and Whittington, 2012) and considering strategy as action emerging over time as strategic intent collides with and accommodates the realities of external forces (Mintzberg, 1973).

We also included a day on coaching and mentoring, exploring concepts such as presence (Nevis, 1987), deep listening, questioning, mirroring and rapport building, but also distinguishing between 'figure' and 'background'. Figure relates to what you are really focusing on right now, including your feelings, beliefs or cognition and how they affect your decision making, whereas background relates to the context the figure works within, by doing this we can expose attention blocks (Bluckert, 2015) thereby exposing insights that can promote personal growth.

Research Methods and Dissertation. We brought to the attention of participants a range of research methodologies and methods, but with a focus on action research, employing ALS as a means of supporting the development of the research proposal and later the dissertation.

\section{What happened}

Here we highlight two significant examples of practice. 


\section{Developing Concepts, Language and a Shared Understanding}

One element we found useful was helping the group to develop and understand the meaning of concepts and the use of language. To achieve this, in some of our sessions we devoted time to clarifying and exploring words and concepts such as: reflection, listening, insights, context, empathy, complexity, simple, simplistic, praxis and practice. We also explored the nature of concepts such as the interconnectedness of variables and the emergent qualities from those interconnections (Bhoyrub, 2010). In so doing we built a collective and agreed lexicon of meaning so that participants acquired a deeper linguistic repertoire of tools that could be applied to their work.

We asked participants to reflect on and share their understanding of each word. We found that they fully engaged in these exercises because they provided clarity of definition and developed a shared understanding and conceptual scaffolding. These interventions gave them time to pause and reflect on meaning. One participant commented,

It was good to take time, just to stop and take stock of my understanding of words [...] just check my previous assumptions [...] I do not think I had ever done that before.

Another commented in a later module that insights into the nuances of definitions had made him more aware of the impact of words on meaning making:

When I am reading now, if am not quite sure about a word I like to just check the meaning [...] I have found this raised my attention to paying attention to what I am actually reading and its real meaning.

One factor that we found useful was the military background of some members of the teaching team. This meant that we were able to 'translate' civilian management theory and practice by incorporating relevant military jargon and management tools. It was thus possible to link what was taught to the teachers' own personal development and transition into the civilian world. Not only did this help with general understanding; it also contributed to setting the tone and way we all worked together. In the groups we actively shared our own stories and this helped to impart a sense of collegial kinship. We found this practice useful and we also found that the way we talked provided validity for the participants. One commented that 'it was good seeing the link you made to military decision making and the orders process' and 'civvy speak makes more sense now'. Another said, 'I didn't realise I've been using decision making tools for years,' and another, 'I feel I have a better handle on my options for my next career'.

Developing a habit of reflection across the modules was important as it helped to promote positive interdependence, with participants willing to share their experiences. We found that the ALS 
helped to surface personal transition and enhance understanding and strengthen rapport. Conversations deepened, moving the focus to a greater awareness of the personal impacts of change and exposing the 'inner game' (Gallwey, 2000; Bluckert, 2006) rather than just external events.

Non-military tutors were introduced in the second module and we found that the conversations developed further as these tutors posed alternative perspectives and questions, requiring participants to give richer descriptions of their assumptions and experiences, thereby helping to bring to the surface deeper insights and on occasions provide unexpected connections.

We found that the development of a common understanding not only resolved issues of definition, but started to raise awareness of the complexity and interconnectedness of the learning environment. It also highlighted the importance of-power of group dialogue. We found that, because time was provided to talk, listen, share and reflect, a more creative and collaborative environment was created. The day-to-day interactions shaped a collective sense-making narrative (Whittle and Mueller, 2012) as participants collectively constructed (or made real) their world (Weick, 2001), but we also found that different horizons emerged.

\section{FF Linking to Action Learning Sets}

The FF session served to raise awareness of the nature of experiential learning, in the process helping participants to take stock of current events and project the future, taking into account the ramifications and interplay of external factors. We found that participants initially took a top-down strategic view of change but, as they progressed, they started to raise deeper questions regarding personal impact and consequences. This in turn enabled them to make novel links and develop insights about themselves and their organisation. For example, when considering the question, 'Will the military continue to decline?' a female participant in the first action learning set raised the issue of the menopause in the military. This comment acted as a catalyst for the discussion, stimulating a cascade of questions about the military and its accepted cultural norms. Such debate helps to develop openness and makes it easier for students to share their thoughts.

The above participant highlighted structural changes in the military and how they had impacted on the expectations and demands on service for its personnel. She noted that these changes were the result of external pressures such as cost saving, but that they had been triggered by the changing attitudes among young people to military service, which had led to a dramatic reduction in the recruitment and retention of personnel. There was therefore a shortage of talent and skills, vacancies for key jobs and gaps in training and operational teams. According to the participant, the military's response to this situation had been to offer extensions of service to personnel, with an option to re-enlist up to their 57th birthday. The participant argued that this move had had an unforeseen impact on her and other female personnel because it had effectively brought the menopause into service life! She contended that the 'menopause could well effect the decision-making ability of key decision makers 
within a unit' and further that this 'can affect decision-making and communications at all levels from corporals to colonels'. It was thus an important factor that could impact on both a peacetime and an operational military force. The participant also considered the 'personal impacts' on her own 'inner wellbeing', and not just on her functionality as a middle-ranking leader, raising issues such as selfdoubt, mood swings and insomnia that could impact on individual and team performance.

After the participant had expressed her views, there was a distinct moment of silence among male members of the group. They appeared surprised and unprepared for the revelation (one commented out of the session that 'this was very left of field'). The tutor developed the concept of the 'here and now' (Bluckert, 2006), getting the group to explore their interpretations and experiences and to reflect on their preconceived assumptions and how the participant's comments had challenged their thinking. All agreed that the revelation was unexpected and raised something they had never considered in a military context. One commented that this was remarkable, as they 'all worked with female personnel back in the unit'. No one could remember being part of a conversation about the menopause back at their unit; one participant said, 'Maybe we should be raising the question with senior commanders.' These comments led naturally into a discussion of the entrenched nature of corporate culture and how we can become encultured (culturally doped, (Raelin 2008)), unconsciously taking on the role of powerless bystander or collaborative perpetuator.

The participants were supportive and positive throughout the discussion, which helped to bring out other connected issues - for example, the demands of military life. The challenge of 'gap posting' was raised - that is, when, due to personnel shortages, key appointments in the military may not be filled for several months and the job has to be covered pending the new appointment. It was noted that teams might have to cover several gap-postings at the same time, or that token replacements might be brought in to provide cover for a few days or weeks before being moved on again.

All agreed that such events increased work pressure and stress, which could be worse for those going through the menopause. The conversation brought out factors relating to cultural climate and how norms and practice could shift unnoticeably over time. It also highlighted how, even though it is changing, the military remains very much a male-dominated environment reflecting a patriarchal world view, which in turn raised broader questions.

It may be of interest to note that the participant who raised the issue is now undertaking a dissertation on the subject of the menopause, and this topic has been raised in other meetings within the military.

\section{Our insights?}

It was interesting to see how AL helped to enable a powerful and critical discussion, and that, over time, participants appeared more confident about exploring the challenges, ambiguities and complexities of the professional world (Korthagen, 2004). A revelation was the nature and the amount of unforeseen consequences at the strategic, organisational and personal levels that were surfaced by the group and 
the way these insights shaped the focus of their work-based assignments and working practice. Discussions such as that described in the preceding section brought out the emergent qualities of interconnections and demonstrated that outcomes arise as much from the relationship between variables as from their intrinsic characteristics (Radford, 2006). They also showed how people build their understanding through dialogue and therefore reinforced the power of ALS.

The introduction of FF proved valuable as a means of encouraging people both to reflect on their time horizons and to take a strategic and personal look at their world. It thus provided a context in which to explore the interconnected nature of time and events, and stimulated students to reflect on their own careers and set assumptions, so prompting them to perceive alternative routes and actions. Overall, FF added richness to the ALS and in part provided a 'contact' in the Gestalt sense (Pelham, 2015) so that participants (including tutors) appeared to be fully absorbed and engaged in the moment and the mood of AL. We engaged in various powerful conversations that often fed directly into the participants' work-based practice, as evidenced in their assignments.

Progressively, throughout the programme, participants appeared to make connections between their assumptions, aspirations, feelings and behaviours and their impact. We found that the AL and FF components encouraged participants to reframe their experiences, take more active control of their professional practice, and actively engage with their senior leaders to effect organisational change.

\section{References}

Anderson, M.L., Goodman, J. \& Schlossberg, N.K. (2012). Counselling adults in transition: Linking Schlossberg's theory with practice in a diverse world, 4th Ed. New York: Springer Publishing Company, LLC.

Armstrong J. S. (1985). Long-Range Forecasting, 2nd edn. Internet version on https://repository.upenn.edu/cgi/viewcontent.cgi?article=1227\&context=marketing_papers [Accessed Jan 2020].

Berle, A. and G. Means, (1932). The Modern Corporation and Private Property, New York, Macmillan. Bhoyrub, J., Hurley, j., Neilson, G. R., Ramsay, M. and Smith, M. (2010) Heutagogy: An alternative practice-based learning approach, Nurse Education in Practice 10(6):322-6.

Bluckert, P. (2006). Psychological Dimensions to Executive Coaching (Coaching in Practice), Open University Press

Bluckert, P. (2015). Gestalt Coaching: Right Here, Right Now, Open University Press

Brennan, J. \& Little, B. (2006). Towards a strategy for workplace learning. Milton Keynes: Open University Centre for Higher Education Research and Information.

Bruner, J. S. (1960). The process of education. Harvard University Press. 


\section{Cousin, G. (2006). An introduction to threshold concepts, Planet, 17(1): 4-5}

Cuhls, K. (2003). From Forecasting to Foresight Processes - New Participative Foresight Activities in Germany, Journal of Forecasting 22, 93-111

Donaldson, L., (1990). The ethereal hand: organizational economics and management theory, Academy of Management Review, 15, 369-381.

Freeman, R. \& McVea, J. (2001). A Stakeholder Approach to Strategic Management. SSRN

Ecclestone, K., Biesta, G. \& Hughes, M. (2010). Transitions in the lifecourse: The role of identity, agency and structure. In K. Ecclestone, G. Biesta \& M. Hughes (Eds.), (pp. 1-15). Transitions and Learning through the Lifecourse. London: Routledge

Freeman, R. E. (1984). Strategic management: A stakeholder approach. Boston: Pitman

Gallwey, T. W. (2000). The Inner Game of Work: Overcoming Mental Obstacles for Maximum Performance, Texere Publishing

Gavigan J. P., Scapoio F., Keenan M., Miles I., Farhf F., Lecoq D., Capriati M., Di Bartolomeo T., (2001). Practical guide to regional foresight, FOREN Network [online] foresight.jrc.ec.europa.eu/documents/eur20128en.pdf (accessed: 25/12/19)

Goodman, J., Schlossberg, N. K., \& Anderson, M. L. (2006). Counseling adults in transition: Linking practice with theory. (3 rd ed.). New York: Springer Publishing Company.

Higate, P. (2003). 'Soft clerks' and 'hard civvies': Pluralizing military masculinities. In P. Higate (Ed.), Military masculinities: Identity and the state (pp. 27-43). Westport, CT: Praeger

Hines, A. \& Gold, J. (2014). An organizational futurist role for integrating foresight into corporations. Technological Forecasting and Social Change. 101. 10.1016/j.techfore.2014.04.003.

Jarzabkowski, P. (2005). Strategy as Practice: An Activity-Based View. UK: Sage.

Jensen, M.C. and W.H. Meckling, (1976), Theory of the firm: managerial behaviour, agency costs, and ownership structure, Journal of Financial Economics, 3, 305-360.

Korthagen, F. A. (2004). In search of the essence of a good teacher: Towards a more holistic approach in teacher education. Teaching and Teacher Education, 20(1): 77-97.

Meyer J, Land R. (2003). Threshold Concepts and Troublesome Knowledge: Linkages to Ways of Thinking and Practising Within the Disciplines. Edinburgh: University of Edinburgh, School of Education.

Miles, I. and Keenan, M. (2003). Practical Guide to Regional Foresight in the UNITED KINGDOM, FOREN project, EC, https://www.academia.edu/4126002/Practical_Guide_to_Regional_Foresight Mintzberg, H. (1973). The Nature of Managerial Work. New York: Harper \& Row.

Nevis, Edwin. (1987). Organizational Consulting: A Gestalt Approach. New York: Gardner Press. 
Pelham, G. (2015). The Coaching Relationship in Practice, SAGE Publications Ltd

Radford, M., (2006). Researching classrooms: complexity and chaos. British Educational Research Journal 32 (2), 177-190.

Raelin, J.A. (2008). Work-Based Learning: Bridging Knowledge and Action in the Workplace, JosseyBass; New and Revised edition

Schlossberg, N.K. (1984). Counseling adults in transition: Linking Practice with Theory. New York, New York: Springer Publishing Company, Inc.

Shotter, J. (2006). Understanding Process From Within: An Argument for 'Withness'Thinking. Organization Studies, 27(4), 585-604. https://doi.org/10.1177/0170840606062105

Teece, D. (2007). Explicating dynamic capabilities: the nature and microfoundations of (sustainable) enterprise performance. Strategic Management Journal, 28(13) 1319 - 1350

Vaara, E., and Whittington, R. (2012). Strategy-as-practice: Taking social practices seriously. Academy of Management Annals, 6, 285-336.

Whittle, A. and Mueller, F. (2012). Bankers in the dock: Moral storytelling in action. Human Relations 65(1): 111-139

Whittington, R. (1996). Strategy as Practice, Long Range Planning, 29 (5) 731-735,

Weick, K. E., (2001). Making Sense of the Organization. Oxford: Blackwell. 
Figure 1. The Korthagen Onion Model.

Source: Korthagen (2004).

Figure is supplied in separate PPT file 
Table 1. FF projections: 'Will the military continue to decline?' (2029-2024-2019).

\section{Outcomes:}

- $\quad$ Retention remains an issue. Military continues to decline despite increase in recruitment.

- Technology generally continues to advance at a rapid pace, partly driven by the need to relieve shortages in personnel.

- Defence Budget rebalance between equipment and manning.

- Technology replaces personnel. Unmanned vehicles/drones.

\section{Outcomes:}

- $\quad$ Retention remains an issue. Recruitment will be streamlined.

- $\quad$ Closure of training centres.

- Non-infantry basic training realigned for cost and efficiency savings.

- Establishment of more drone squadrons.

- Infantry battalions amalgamated under one cap badge.

\section{Outcomes:}

- Contracts being offered for return to service. Increase in age for army service.

- Restructuring of current military training centres.

- Warships require less manpower to be operationally effective.

- Amalgamation of military generic trades as the pool of people gets smaller. 